\title{
SURVIVAL AFTER CARDIOPULMONARY RESUSCITATION AND FACTORS INFLUENCING IT IN THE EMERGENCY DEPARTMENT OF A TERTIARY CARE HOSPITAL IN BANGALORE, INDIA
}

\author{
Alan de Lima Pereira ${ }^{1}$, Girish Narayan², Shakuntala Murty 3 \\ 1 Junior Resident, Department of Emergency Medicine, St. John's Medical College and Hospital. \\ ${ }^{2}$ Associate Professor, Department of Emergency Medicine, St. John's Medical College and Hospital. \\ 3Professor, Department of Emergency Medicine, St. John's Medical College and Hospital.
}

\section{ABSTRACT}

\section{PURPOSE}

Sudden Cardiac Arrest (SCA) is a major cause of mortality and morbidity in the emergency department. Cardiopulmonary resuscitation by trained providers in a case of cardiac arrest has been proven to have survival benefit across the world. Many studies have been done regarding predictors of survival outcomes in SCA yet little data exists from India The objective of this study was to evaluate the related factors, outcome, and survival rate in patients with cardiac arrest who received Cardiopulmonary Resuscitation (CPR) at the Emergency Medicine Department of a tertiary care centre in India.

\section{METHODS}

This retrospective cohort study included all patients who were older than 15 years with sudden cardiac arrest and who were resuscitated in the emergency room between January 2014 and June 2014. STATA 11 analytical software was used to analyse factors that related to the sustained Return of Spontaneous Circulation (ROSC) and survival at discharge.

\section{RESULTS}

There were 41 patients enrolled. The overall sustained ROSC rate was $56.1 \%$ and the survival rate at discharge was $14.63 \%$. Statistically significant factor related to sustained ROSC was younger age of the patient. Those requiring a lesser duration of CPR were found to be more likely to survive. In out-of-hospital cardiac arrests, bystander initiated CPR was not documented in a single case.

\section{CONCLUSION}

Factors associated with sustained ROSC were age of the patient and the duration of CPR. Recruitment of a larger sample size should continue so that more accurate findings are obtained. Basic Life Support training so that more bystanders initiate CPR at the site of an SCA is a pressing need in India

\section{KEYWORDS}

CPR, Cardiac Arrest, Predictors, Emergency Department.

HOW TO CITE THIS ARTICLE: Pereira ADL, Narayan G, Murty S. Survival after cardiopulmonary resuscitation and factors influencing it in the emergency department of a tertiary care hospital in Bangalore, India. J Evolution Med Dent Sci 2016;5(3): 173-176, DOI: $10.14260 /$ jemds/2016/40

\section{INTRODUCTION}

Sudden Cardiac Arrest (SCA) is a major cause of mortality and morbidity in the emergency department. Cardiopulmonary resuscitation by trained providers in a case of cardiac arrest has been proven to have survival benefit across the world.(1),(2) Many studies have been done regarding predictors of survival outcomes in SCA yet little data exists from India and other parts of the developing world and other parts of the developing world.(3),(4),(5),(6)

In this study, we aim to look at the effectiveness of cardiopulmonary resuscitation when performed according to the American Heart Association's Advanced Cardiac Life Support (ACLS) 2010 guidelines.(7) in the emergency department of a tertiary care hospital in Bangalore, India over a period of 6 months from January 2014 to June 2014. We then attempt to ascertain the factors that independently determine the occurrence of a favourable outcome.

Financial or Other, Competing Interest: None.

Submission 14-11-2015, Peer Review 16-11-2015,

Acceptance 11-12-2015, Published 08-01-2016.

Corresponding Author:

Dr. Alan de Lima Pereira,

House No. 1/F Ximbhat,

Maina-Curtorim-403709,

Goa, India.

E-mail: dr.a.d.pereira@gmail.com

DOI:10.14260/jemds/2016/40
Based on our findings we then formulate some recommendations to further improve the survival likelihood of patients having a cardiac arrest in an emergency department in a similar setting as ours.

\section{METHODOLOGY}

The study site was a 1200 bedded tertiary care hospital in the metropolitan area of Bangalore city and has a fully equipped emergency department that has an average turnover of more than 100 patients per day. The resuscitation team consisted of 5-6 members at least two of whom (but often more) are ACLS certified. In the emergency department a register is maintained for all patients undergoing cardiopulmonary resuscitation. This record along with supplemental data from their medical records documenting further course in the hospital was analysed for the purpose of this study.

Patient characteristics such as age, sex, and previous medical history, Cerebral Performance Categories score (CPC).(8) before cardiac arrest, location of cardiac arrest, bystander witnessed arrest, bystander CPR performed, first documented pulseless rhythm, time interval from collapse/arrival to start of CPR in minutes, CPR duration, time of arrest, initial cause of cardiac arrest and total ampoules of adrenalin used were recorded. 
The initial outcomes of CPR were categorized as no Return of Spontaneous Circulation (ROSC), do not attempt resuscitation (Order in the emergency room), ROSC for more than or equal to 20 minutes or sustained ROSC. Patients with sustained ROSC were then followed up and categorised as death in hospital or survival at discharge. Some patients were also discharged against medical advice while others were transferred out of the emergency department due to nonavailability of Intensive Care Unit (ICU) beds at the time.

\section{Study Design}

Retrospective Cohort Study.

\section{Inclusion Criteria}

1. Received cardiopulmonary resuscitation within the emergency department.

2. Witnessed and unwitnessed cardiac arrests were both included. Patients were either wheeled in with no central pulse and resuscitation efforts begun in the emergency department or were patients under observation in the emergency department who had a witnessed cardiac arrest.
3. Arrest occurred between 1st January 2014 and 30th June 2014-06-25.

\section{Exclusion Criteria:}

1. Patients below 15 years of age.

2. Out-of-hospital arrests that were deemed to be nonsalvageable or brought dead by the treating physician and in whom no cardiopulmonary resuscitation was attempted.

3. Patients in whom prior consent was taken to withhold active resuscitation and life support.

4. Patients where no documented evidence of cardiopulmonary resuscitation in the emergency department could be traced.

Data was reported on an adapted version of the Utstein templates provided by the AHA.(9) and then transcribed into a Microsoft Excel worksheet. Using STATA 11 statistical software, student ' $\mathrm{t}$ ' test, Chi square test and Fisher's exact test were carried out as appropriate and the results analysed.

\section{RESULTS}

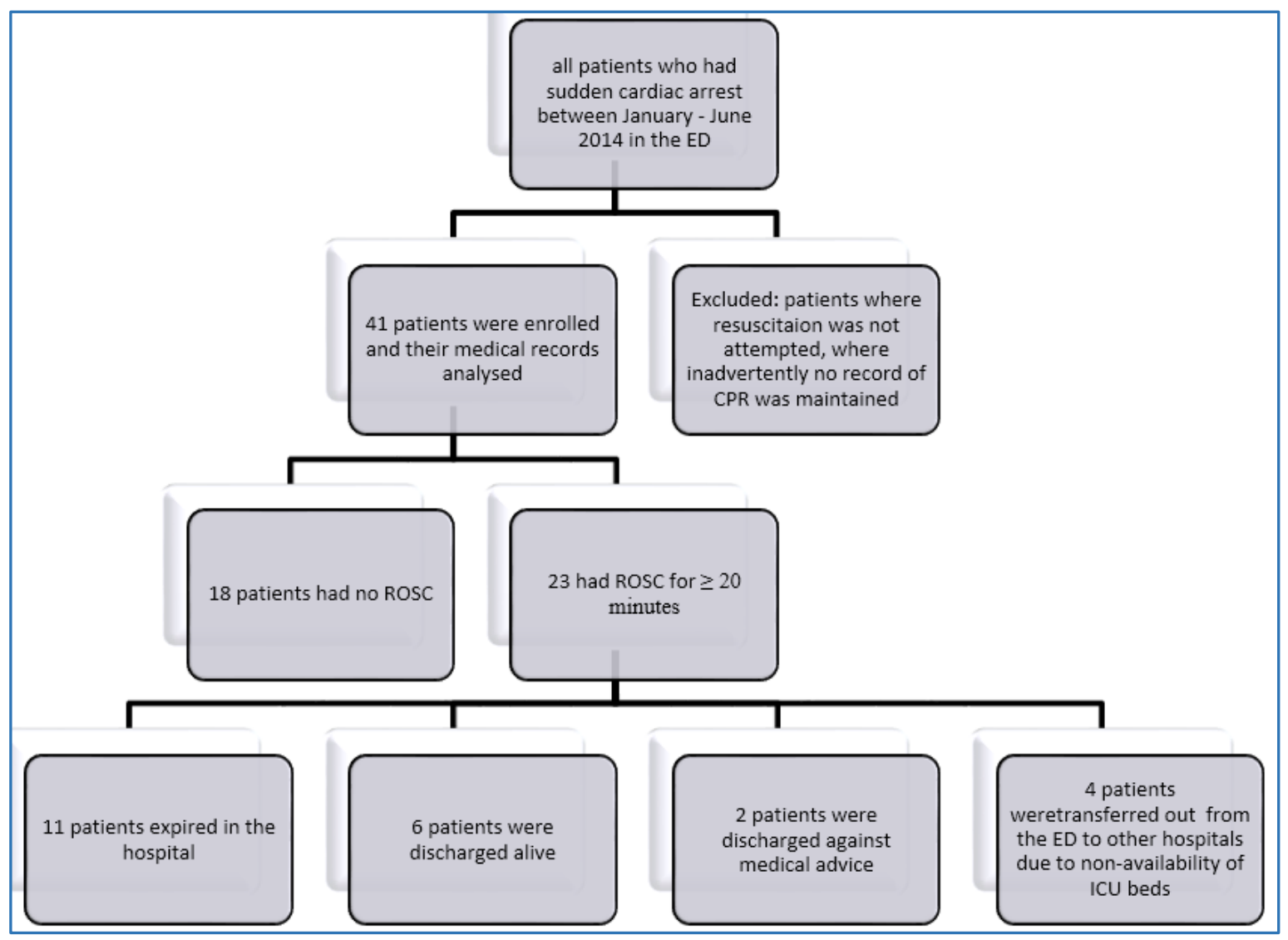

Table 1: Flow Diagram of the Study

\section{ABBREVIATIONS}

CPR, cardiopulmonary resuscitation; ED, emergency department; ROSC, return of spontaneous circulation.

During the study period, there were 41 patients diagnosed to have SCA and who received CPR in the emergency department. This excludes patients in whom no CPR was performed or those in whom inadvertently no record of CPR was maintained. Of the 41 patients, no ROSC was achieved in
18 patients ( $43.9 \%$ ) while 23 patients $(56.1 \%)$ had a sustained ROSC for more than 20 minutes.

Of the 23 patients with sustained ROSC, 11 patients (47.8\%) expired in the hospital, 6 patients (26.1\%) were discharged alive, 2 patients $(8.7 \%)$ were discharged against medical advice post admission and 4 patients (17.4\%) were transferred out of the emergency department itself due to nonavailability of intensive care unit beds in our hospital. 
Of the 6 patients discharged alive only one had a CPC score $>3$ after suffering hypoxic brain injury as a consequence of CPR. The rest had a CPC score of 1 or 2 .

Clinical characteristics of patients with and without ROSC were compared (Table 4). Two factors that were found to be significantly associated with sustained ROSC were a younger age and those who needed a shorter duration of CPR for achievement of ROSC. All other factors that were compared in Table 4 such as location of arrest, first documented pulseless rhythm and suspected initial cause of arrest were not found to have a statistically significant association with ROSC.

In out-of-hospital cardiac arrests, bystander initiated CPR was not documented in a single case.

\begin{tabular}{|c|c|c|c|c|}
\hline \multirow[b]{2}{*}{ Characteristics } & \multicolumn{2}{|c|}{ Sustained ROSC $\geq 20$ minutes } & \multirow[b]{2}{*}{ P-value } & \multirow{2}{*}{$\begin{array}{l}6 \text { Discharged Alive, } n(\%) \\
\text { (Subset of Success } n=23 \text { ) }\end{array}$} \\
\hline & $\begin{array}{c}18 \text { Failure, } \\
\text { n (\%) }\end{array}$ & $\begin{array}{c}23 \text { Success, } \\
\text { n (\%) }\end{array}$ & & \\
\hline \multicolumn{5}{|l|}{ Sex } \\
\hline Male & 15 (83.33) & $20(87)$ & \multirow{2}{*}{1.0000} & $6(100)$ \\
\hline Female & $3(16.67)$ & $3(13)$ & & $0(0)$ \\
\hline Age (years), mean $\pm 2 \mathrm{SD}$ & $56.9 \pm 29.1$ & $44.34 \pm 31.6$ & 0.0126 & $43.2 \pm 37.9$ \\
\hline \multicolumn{4}{|c|}{ Medical History* } & \\
\hline Hypertension & $1(5.5)$ & $7(30.4)$ & 0.0594 & $2(33.33)$ \\
\hline Diabetes Mellitus & $4(22.2)$ & $7(30.4)$ & 0.7262 & $2(33.33)$ \\
\hline Encephalopathy & $0(0)$ & $2(8.7)$ & 0.4951 & $1(16.67)$ \\
\hline Intrinsic Heart Disease & $3(16.67)$ & $1(4.3)$ & 0.3030 & $1(16.67)$ \\
\hline Pulmonary Disease & $2(11.1)$ & $3(13.0)$ & 1.0000 & $1(16.67)$ \\
\hline Liver Disease & $0(0)$ & $5(21.7)$ & 0.0563 & $1(16.67)$ \\
\hline Renal Disease & $1(5.5)$ & $1(4.3)$ & 1.0000 & $1(16.67)$ \\
\hline Malignancy & $0(0)$ & $1(4.3)$ & 1.0000 & $0(0)$ \\
\hline Haemophilia & $1(5.5)$ & $0(0)$ & 0.4390 & $0(0)$ \\
\hline Unknown/Not Collected & $4(22.2)$ & $2(8.7)$ & 0.3773 & $0(0)$ \\
\hline \multicolumn{4}{|c|}{ CPC score before cardiac arrest } & \\
\hline 1 and 2 & $16(88.89)$ & $17(73.91)$ & \multirow{2}{*}{0.4290} & $5(83.33)$ \\
\hline 3 and 4 & $2(11.11)$ & $6(26.09)$ & & $1(16.67)$ \\
\hline \multicolumn{4}{|c|}{ Location of cardiac arrest } & \\
\hline Out-of-Hospital & $9(50)$ & $8(34.8)$ & \multirow{2}{*}{0.3583} & $3(50)$ \\
\hline In-Hospital & $9(50)$ & $15(65.2)$ & & $3(50)$ \\
\hline Witnessed Arrest & $14(77.78)$ & $20(86.95)$ & 0.6786 & $6(100)$ \\
\hline Bystander performed CPR & $9(50)$ & $18(78.26)$ & 0.0969 & $4(66.67)$ \\
\hline \multicolumn{5}{|c|}{ First documented pulseless rhythm } \\
\hline Non-shockable & $13(72.22)$ & $18(78.26)$ & \multirow{2}{*}{0.7245} & $4(66.67)$ \\
\hline Shockable & $5(27.78)$ & $5(21.74)$ & & $2(33.33)$ \\
\hline $\begin{array}{l}\text { Collapse to start CPR (minutes) } \\
\text { median (minimum, maximum) }\end{array}$ & $1(1,80)$ & $1(1,20)$ & 0.0756 & $1(1,10)$ \\
\hline \multicolumn{5}{|c|}{ Collapse to start CPR } \\
\hline$<10$ minutes & $14(77.78)$ & $21(91.3)$ & \multirow{2}{*}{0.3773} & $5(83.33)$ \\
\hline$\geq 10$ minutes & $4(22.22)$ & $2(8.7)$ & & $1(16.67)$ \\
\hline $\begin{array}{r}\text { Table 2: Clinical } \\
\text { ROSC }\end{array}$ & $\begin{array}{l}\text { cteristics of a } \\
\text { re than } 20 \mathrm{~m}\end{array}$ & $\begin{array}{l}\text { den cardiac } \\
\text { and by sur }\end{array}$ & t patient & ined \\
\hline
\end{tabular}

\begin{tabular}{|c|c|c|c|c|}
\hline \multirow[b]{2}{*}{ Characteristics } & \multicolumn{2}{|c|}{ Sustained ROSC $\geq 20$ minutes } & \multirow[b]{2}{*}{ P-value } & \multirow[b]{2}{*}{$\begin{array}{l}6 \text { Discharged Alive, } n(\%) \\
\text { (Subset of Success } n=23 \text { ) }\end{array}$} \\
\hline & $\begin{array}{c}18 \text { Failure, } n \\
(\%)\end{array}$ & $\begin{array}{c}23 \text { Success, } n \\
(\%)\end{array}$ & & \\
\hline $\begin{array}{l}\text { CPR duration (minutes) median } \\
\text { (minimum, maximum) }\end{array}$ & $27(12,60)$ & $5(2,45)$ & $<0.0001$ & $4.5(2,33)$ \\
\hline \multicolumn{4}{|c|}{ Initial Cause of Arrest } & \\
\hline Cardio-pulmonary & $12(66.67)$ & $13(56.52)$ & \multirow{2}{*}{0.5396} & $5(83.33)$ \\
\hline Non-cardiopulmonary & $6(33.33)$ & $10(43.48)$ & & $1(16.67)$ \\
\hline $\begin{array}{l}\text { Adrenaline (ampoules) median } \\
\text { (minimum, maximum) }\end{array}$ & $5.5(1,14)$ & $2(1,7)$ & $<0.0001$ & $1.5(1,3)$ \\
\hline
\end{tabular}

\section{DISCUSSION}

One of the limitations of this study is that all patients who received CPR were not recruited as medical documentation of a small unknown number could not be traced. This is more so in the case of patients who might have achieved ROSC and got admitted as those who expired in the emergency department were traced back from mortality audits. This may account for a decrease in the number of patients where ROSC was successfully achieved and consequently for the number of patients that might have been discharged alive.

Due to the short duration of the study, we also have a limited sample size. It would be well advised to carry this study forward prospectively and reanalyse the data with a larger sample size at a later date. Mechanisms have been put in place 
for more complete recruitment of subjects so that it reflects in the results accurately.

Of note was the fact that in out of hospital arrests, not a single patient received CPR from bystanders. Several studies in the past have proven the increase in favourable outcomes in patients who receive CPR from bystanders before arrival of the emergency medical services. Further efforts have to be made in our country to increase training in basic life support for civilians.

As many members of the resuscitation team were trained as per ACLS guidelines, that may have helped improve the outcomes of CPR.

While the number of ampoules of adrenaline used in the two groups was significantly different in univariate analysis, it was an insignificant finding on multivariate modelling as it was found to be dependent on the duration of CPR (as per ACLS protocol).

There is a significant association between age and ROSC with younger patients more likely to survive. This may be due to a multitude of factors including lesser co-morbidities.

\section{CONCLUSION}

Younger patients and those requiring a lesser duration of CPR for achieving a sustained ROSC were more likely to survive.

Recruitment of a larger sample size should continue so that more accurate findings are obtained.

Basic life support training so that more bystanders initiate CPR at the site of an SCA is a pressing need in India.

\section{BIBLIOGRAPHY}

1. Hollenberg J, Herlitz J, Lindqvist J, Riva G, Bohm K, Rosenqvist $\mathrm{M}$, et al. Improved survival after out-ofhospital cardiac arrest is associated with an increase in proportion of emergency crew-witnessed cases and bystander cardiopulmonary resuscitation. Circulation. 2008;118(4):389-396.

2. Sodhi K, Shrivastava A, Singla M. Impact of advanced cardiac life support training program on the outcome of cardiopulmonary resuscitation in a tertiary care hospital. Indian Journal of Critical Care Medicine. 2011;15(4):209.
3. Sawanyawisuth K, Sittichanbuncha Y, Prachanukool T. A 6-year experience of CPR outcomes in an emergency department in Thailand. Therapeutics and Clinical Risk Management. 2013;377.

4. Chakravarthy M, Mitra S, Nonis L. Outcomes of inhospital, out of intensive care and operation theatre cardiac arrests in a tertiary referral hospital. Indian Heart Journal. 2012;64(1):7-11.

5. Rajaram R, Rajagopalan RE, Pai M, et al. Survival after cardiopulmonary resuscitation in an urban Indian hospital. Natl Med J India 1999;12(2):51-55.

6. Cooper S, Janghorbani M, Cooper G. A decade of inhospital resuscitation: Outcomes and prediction of survival? Resuscitation. 2006;68(2):231-237.

7. Field J, Hazinski M, Sayre M, Chameides L, Schexnayder S, Hemphill R, et al. Part 1: Executive Summary: 2010 American Heart Association Guidelines for Cardiopulmonary Resuscitation and Emergency Cardiovascular Care. Circulation. 2010;122(18_suppl_3):S640-S656.

8. Stiell I, Nesbitt L, Nichol G, Maloney J, Dreyer J, Beaudoin $\mathrm{T}$, et al. Comparison of the cerebral performance category score and the health utilities index for survivors of cardiac arrest. Annals of Emergency Medicine. 2009;53(2):241-248.e1.

9. Jacobs I. Cardiac arrest and cardiopulmonary resuscitation outcome reports: Update and simplification of the Utstein Templates for resuscitation registries: A Statement for Healthcare Professionals from a Task Force of the International Liaison Committee on Resuscitation (American Heart Association, European Resuscitation Council, Australian Resuscitation Council, New Zealand Resuscitation Council, Heart and Stroke Foundation of Canada, InterAmerican Heart Foundation, Resuscitation Councils of Southern Africa). Circulation. 2004;110(21):3385-3397. 